\title{
ENGELAND'S „BOTERMARKT” IN VERBAND TOT NEDERLAND'S „BOTERBELANG.”
}

In 't Landro. Wochenblatt für Schleswig-Holstein, nr. van 25 Nov. van de hand des redacteurs, tevens algemeen secretaris van de Sleeswijk-Holsteinsche Landbouw-vereeniging, den bekwamen deskundige Boysen, te $\mathrm{Kiel}$, is een uittreksel verschenen van een door hem, einde October ll., aan den Minister van Landbouw enz. vitgebracht rapport. Omdat zulks ook voor ons land van groote beteekenis is, heeft steller dezes zich beijverd daarvan spoedig een referaat te geven, waaraan hij eenige opmerkingen toevoegen mag.

De Hr. Boysen begint met te vragen, of de Engelsche botermarkt van dien aard is, dat 't de moeite loont er zich voor in te spannen, ten einde er meer en meer te huis te geraken en er dus ook hoe langer hoe meer van te genieten. Die vraag beant woordt hij bevestigend. Want Fngeland - de feitelijke toestand bevestigt het - kan voorshands en ook nog wel geruimen tijd geen invoer missen.

De invoer van boter bedroeg volgens hem in:

$18842,472,567$ centen. à $12,526,293$ pd. st. waarde.

$18851,553,302 \pi n 8,506,204, n$ n

$18861,543,404 \pi n 8,140,188 \pi n$ n

Het groote verschil der bedragen over 1884 en de beide volgende jaren is een gevolg van het feit, dat te beginnen met 1885 in Engeland boter en butterine (zoogen. kunstboter) afzonderlijk in de invoerstaten voorkomen. (*)

Van deze butterine werd ingevoerd in

1885 tot 847,263 cent., ter waarde van $3,054,679 \mathrm{pd}$. st.

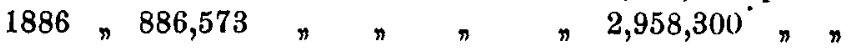

Telt men deze opgaven op bij den boter-invoer van de resp. jaren, dan verkrijgt men de bedragen in:

$\left(^{*}\right)$ Tot onze niet te berekenen schade zijn wij iu dit opricht nog steeds "iu culpa." 'T'rouwens Nederland komt wel eens meer "achteraan."

LCON. 1887 . 
$18852,400,565$ cent., ter waarde van $11,560,863$ pd. st.

$18862,429,977 n n$ n $n 11,098,488 n$ n

Hieruit volgt, dat binnen 3 jaren de gezamelijke invoer om ongeveer 42,000 cent. achteruit is gegaan, terwịl de gezamelijke waarde van den algeheelen boter-invoer (inclusive butterine e. t. q.) met $1,427,805$ pd. st. achteruit is gegaan.

Kan men niet ontkennen, dat de pogingen der Engelsche landbouwers, om de melkproductie en vooral de tot heden niet genoeg in 't oog gehouden boter-voortbrenging met beter succes te ontwikkelen - toch blijkt uit al wat derwaarts wordt vernomen, dat er geen snelle of krachtige meerdere eigen-productie in 't Vereenigd Koninkrijk te wachten is. De betrekkelijk anzienlijke verlaging van 't geldelijk bedrag der boterinvoeren blijkt uit het lage standpunt van de prijzen, die binnen de hier besproken 3 jaren ongeveer 20 sh. per centen. achteruit gegaan zijn. Binnen de laatste 15 jaren is de ter consumtie in het Vereenigd Koninkrijk van buitenaf ingevoerde hoeveelheid boter - en butterine - meer dan verdubbeld. In het jaar 1872 bedroeg het plus van den invoer 1,107,963 cent., tegenover $2,348,850$ cent. in 1886 . Tegenover een weder-uitvoer van 30,000 cent. in 1872 staat in 1886 eene hoeveelheid van 81,127 centr.

Deze tamelijk regelmatige, gedurende een 15 tal jaren tot heden toenemende consumtie, die uit de opgegeven cijfers blijkt, is van beteekenis, ook omdat er uit kan worden afgeleid, dat het den producenten in Engeland in den eersten tijd nog wel niet gelukken zal, de in de laatste jaren aangevoerde hoeveelheden door vermeerderd eigen product te ondervangen. Bovendien is eene toename van de boter-productie op meer of min groote schaal zoo veel te onwaarschijnlijker, omdat de verhouding vau het aantal melkkoeien tot dat der inwoners in Engeland zéér klein is, en wegens de prijzen, die voor melk, om voor verseh te gebruiken, betaald worden, het botergemaak niet overal voordeelig genoeg wezen zal. Volgens de veetelling van 1886 in Engeland komen per 100 inwoners 10,8 koeien en vaarzen, tegenover 11,7 in het jaar 1872. Naar Boysen aan de laatste veetelling in Pruissen (anno 1883 ) ontleent, was de verhouding daar toen geheel anders: per 100 inwoners 33,9 stuks groot vee, en in de provincie SleeswijkHolstein zelfs $68,5 .\left(^{*}\right)$ Zulke enorme verschillen kunnen in geen

$\left(^{*}\right)$ Over 1884 bedroeg volgens bet Verslag over den landbouw in Nederland het geheele aantal rundvee in ons land $1,474,4,12$ stuks, waarvan 890,168 melkkoeien, bebalve 493,000 kalveren en pinken, stieren, mestvee. enz.

De bevolking bedroeg over dat jaar $4,225,065$ zieleu. Voor ons land was de verhouding per 100 inwoners toes dus 34,89 rundvee en 21,06 melkkoeien alleen. 
geval anders dan zéér langzaam veranderen. Boysen meent dan ook, dat men minder rekening heeft te houden met de concurrentie van de producenten in Engeland zelf dan wel met de vreemde Rijken, die op de Engelsche markt mee concurreeren. De hoeveelheden te kennen, die door hen worden aangevoerd is dus van groote waarde, te meer, daar sommige hunner - o. a. ook ons vaderland - nog lang niet de grens van hun productie-vermogen schijnen te hebben bereikt. Om die reden moge 't navolgende overzicht van den invoer van boter en butterine over 1885 en 1886 aan Boysen's opstel hier worden ontleend.

\begin{tabular}{|c|c|c|c|c|c|}
\hline \multirow{2}{*}{ a. Boter. } & & \multicolumn{2}{|c|}{1885} & \multicolumn{2}{|c|}{1856} \\
\hline & & centen. & $\bar{E}$ & centen. & $£$ \\
\hline Frankrijk & . & 450,933 & $2,578,618$ & 402,620 & $2,264,001$ \\
\hline Dewemarken. . & . & 377,447 & $2,117,831$ & 400,556 & $2,194,905$ \\
\hline Nederlaud . . & . & 307,861 & $1,661,380$ & 359,013 & $1,775,454$ \\
\hline Duitschland. . & . & 143,482 & 788,899 & 119.154 & 611,548 \\
\hline Zweden . . & . & 128,107 & 723,169 & 148,651 & 801,157 \\
\hline Canada.. . & . & 36,259 & 164,166 & 31,348 & 119,970 \\
\hline Vereenigde Stateu & . & 77,588 & 314,062 & 42,326 & 160,391 \\
\hline Noor'wegen & . & 4,286 & 23,172 & 7,186 & 38,426 \\
\hline Overige Rijken & . & 27,339 & 152,907 & 32,540 & 174,336 \\
\hline $\begin{array}{r}\text { Tataal } \\
\text { b. Butterine. }\end{array}$ & . & $1,553,302$ & $8,506,204$ & $1,543,404$ & $8,140,188$ \\
\hline Nederland . & . & 772,473 & $2,793,516$ & 833,957 & $2,767,599$ \\
\hline Belgie & . & 40,465 & 144,404 & 20,002 & 69,240 \\
\hline Noorwegen & . & 17,411 & 69,995 & 20,875 & 82.582 \\
\hline Zweden. . & . & . & & 34 & 98 \\
\hline Overige Rijken & . & 16,914 & 46,764 & 11,705 & 38,781 \\
\hline Totaal & • & 847,263 & $3,054,679$ & 886,573 & $2, \overline{958,300}$ \\
\hline
\end{tabular}

De meeste aandacht - zoo zegt Boysen - verdient bij de overweging van deze eijfers Denemarken en Nederland; Denemarken voor de groote hoeveelheid ingevoerde boter en Nederland wegens de aanzienlijke hoveelheid ingevoerde butterine (waaronder hier verstaan wordt: zoogen. kunstboter en alle overig "gemeng" van dat smeer met echte boter). En Denemarken! Binnen 12 jaren is de uitvoer van boter ongeveer verdubbeld. Op 1 April 1873/74 bedroeg die volgens ambtelijke cijfers 103,322 tonnen, ongeveer 250,000 centen. - en over 1886 is in Engeland alleen 400,556 cent. boter geïmporteerd!

Volgens de Deensche statistiek bedroeg de geheele uitvoer van boter in het jaar 1886431,218 centen., waarvan 85,840 centen. uit het buitenland ontvangen.

Min of meer overeenkomstig is het gelegen met $Z$ weden. 
Terwijl uit dat Rijk in 1860 de uitvoer van boter circa 20,000 $Z_{w}$. cent. bedroeg, was de uitvoer 10 jaren later 30,000 à 40,000 cent., in 1884 reeds 126,000 en in 1885 ongeveer 172,000 centenaars.

De toeneming van den butterine-uitvoer uit Nederland, zegt Boysen, ook van mengboter uit dat Rijk, is mogelijk geworden door een hoogst aanzienlijken invoer van oleo-margarine aldaar uit Amerika. Alleen van de Vereenigde Staten betrok Nederland in de laatste jaren ongeveer 300,000 centenaars per jaar. (*)

In verband tot de aanzienlijke toeneming van de kunstboterfabrikatie verdient de aandacht - naar Boyson terecht zegt het dalen van de talgprijzen in Duitschland en in Engeland. Hij was in 't bezit van een aan ambtelijke opgaven ontleende cijferreeks betrekkelijk die prijzen, waarvan hij de navolgenden aanteekent:

sh.

1872 per cent. 42,88

$\begin{array}{llll}1873 & n & n & 41,28 \\ 1874 & \eta & n & 40,36 \\ 1875 & n & \eta & 42,30 \\ 1876 & n & n & 42,90 \\ 1877 & n & \eta & 41,96 \\ 1878 & n & n & 39,39\end{array}$

sh.

1879 per cent. 35,87

$1880 \gg \pi \quad 35,12$

$1881 \rightarrow \pi 35,24$

$1882 \rightarrow \pi 40,35$

$1883 \cap \# \quad 40,48$

$1884, \pi \quad 37,78$

$1885, \quad \# 31,32$

$1886 \gg \quad 25,66$

De Hr. Boysen merkt nog 't volgende op: ${ }_{n}^{T}$ Terwijl de gezamelijke uitvoer aan boter uit Nederland in 1876 slechts 229,000 centen. bedroeg, klom dat cijfer in 1885 (voor boter en butterine) tot 633,000 cent., terwijl in gezegd tijdvak het antal koeien niet onaunmerkelijk achteruit was gegaan, bedragende dit in 1875 stuks 923,300 en in 1884 stuks 890,200 ." De bijvoeging "boter en butterine" moet gewaardeerd worden. Eenige jaren geleden is in eene plechtige samenkomst der Zweedsche Landbouw-Akademie, als naar gewoonte door den Koning van Zweden bijgewoond, met ons land de draak gestoken. Een spreker van invloed toonde tabellarisch aan .... hoe de in aantal niet of maar weinig toegenomen koeien in Nederland eensklaps in boterproductie zoo ongeveer 't dubbel hadden geleverd! Natuurlijk is toen de hilariteit opgewekt, gelijk ter zijner tijd is medegedeeld. Trouwens tot heden

$\left(^{*}\right)$ Volgens het Verslag over den landboun in Nederland over 1885, 't laatst verscheueue, vertegenwoordigde de margarine-anuvoer te Rotterdam in 1885 eene waarde vau circa 13 millioen gulden, tegeu ongeveer $12 \frac{1}{2}$ millioen gulden in 1884 . De totale aanvees naar Nederland is daar geschat op $30,400,000$ kilogr. in 1884 en $37,800,000$ kilogr. in 1885 . 
nog zonder eenig gevolg. Terwijl Engeland sedert een 3 tal jaren bij den invoer van boter zeer terecht verschil maakt tusschen 't echte en 't nagemaakte product, voert 't in eigen oogen zoo praktische en in den handel zoo ervaren Nederland onder den naam "boter" alles uit wat lieden met een elastiek gewelen onder dien naam overbrengen - ter prejudice van de oud-hollandsche trouw, die in zake boter althans ook op de Engelsche markt zoo geducht is getaand.

Een eerste stap ter verbetering zou dan ook zeker zijn - gelijk ik eenige jaren geleden te vergeefs aan een invloedrijken regeeringspersoon mocht opmerken $\left({ }^{*}\right)$, om aanteekening te houden van en te waarmerken wat uit ons land wordt uitgevoerd: boter of 't geknoei, waarmee men, onder valschen naam, ons nationaal product tot schade en schande van de Nederlandsche natie in den vreemde, in casu te Londen, zoo ontzettend heeft gedeprecieerd.

Boysen oordeelt scherp, maar zeker zéér juist ook, als hij aan 't eind van zijn artikel schrijft:

„Immerhin haben wir in der Butterine-Fabrikation in Holland, „abgesehen von der verwerflichen Art und Weise der Handels"manipulation ihrer Träger, auf die ich später noch kommen "werde, einen Factor zu erblicken, mit dem zu rechnen ist."

Gewis moet ook met dezen factor rekening gehouden worden. $\mathrm{Na}$ de zoo welwillende woorden, onlangs (Landb. Cour. 9 Oct.) tot mij gericht in zake mijne jaren lang - toch inderdaad niet uit eigenbelang - volgehouden bemoeiingen omtrent den handel in natuurboter, mag ik met eenige vrijmoedigheid voortgaan over dit onderwerp mijne meening te zeggen; ik elk geval handel ik niet wegens of heb ook maar weinig persoonlijk belang met boter of boterhandel, evenmin nu als in de afgeloopen 25 jaren, waarin ik altijd heb gestreefd naar de meest mogelijke onaf han-

(*) Ik veroorloofde mij toen de opmerking, 't navolgende voor noodig te houden.

Bij uitvoer van boter en al wat onder dien naam naar den rreemde gaat: eischen eene ofticieel gewaarmerkte onderteekende verklaring in duplo van wat men voor uitvoer opgeeft. Pleegt men met't geëxporteerde later bedrog, dan zou althans de Regeering, onder welker opzicht de uitvoer plaats had, daarvoor niet verantwoordelijk zijn en harerzijds de eer van 't volk, dat zij vertegenwoordigt, ophouden in den vreemde, in elk geval een krachtige stenn zijn voor eerlijke lieden. Ware toen aan mijn denkbeeld eenige aandacht geschonken, dan zou in elk geval een eind zijn gemaakt aan 't rampzalige feit, dat sedert jaren bij ons boter en alle namaaksels daarvan ouder gelijkluideuden uaam verzonden kuuuen worden. Dat kost aan ons volk millioenen! 
kelijkheid. Mijn doel was en blijft mijnerzijds mee te helpen bijdragen tot herstel - zoo nog mogelijk - van den in zake boter zoo rampzalig verloren "roep" in 't buitenland. Een roep, waarop zich mịn vaderland eenige jaren geleden terecht beroemen mocht.

Hierboven is gezegd, dat men geen rekening had te houden met de concurrentie van de producenten in Engeland, maar wel met de importeurs dáár uit andere Rijken.

En zal men nu met eenig goed gevolg concurreeren, dan moet men waar aanbieden, waarmee men concurreeren kan. Aan dit axioma twịfelt wel niemand. Ook niet aan deze stelling, dat een Rijk, gelijk het onze, zoo nabij de Engelsche markt gelegen en daarmee z6́6 veel voeling onderhoudende, uit den aard der zaak is aangewezen, om duchtig te concurreeren om het hoofd te bieden aan alle overige naburige Rijken - mits onze botermakers maar wakker zijn en niet inslapen.

$\mathrm{Nu}$ de vraag: concurreeren wij? en zoo ja hue doen wij het? Wij concurreeren in hoeveelheid zeker. In 1886 voerden wij in Engeland meer boter in dan in 1885 , zonder nu nog te gewagen van den invoer van de nagemaakte boter. Maar hoe was de hoedanigheid van wat wij invoerden?

Op den voorgrond zet ik, dat om eenigen roep te erlangen op een wereldmarkt 't een eerste vereischte is een zooveel mogelijk uniform product aan te voeren, gelijkmatig in bewerking, kleur, geur en uiterlijk, gewaarmerkt door bekende, door den handel erkende en gerespecteerde verpakking, trouw en eerlijk.

Doen wij - d. i. hier de handel - dat?

Neen! Integendeel: in ons eigen land is er zóó groot verschi] tusschen ter markt gebrachte boter, dat een leek zich daarvan geen voorstelling maken kan.

Zoo'n leek - trouwens ieder, die deze zaak onderzoekt raadpleegt in de eerste plaats 't officieele Landbouro-verslag. (*)

En wat leest men $n u$ in den laatsten daarvan verschenen jaargang (1885), bl. 518 ?

. Uit Harlingen: Telken jare roept de boterhaudel meer dringend om verbeteriug van de qualiteit der Friesche boter, in 't algemeen, en is deze verbetering gebiedend noodig, zal ons product niet langer nchterstana op de Londensche markt, waar Deensche, Fransche eu Italiansche boter, door een meer gelijkmatige, eensoortige bewerking, den voorrang hebben veroverd."

$($ *) Wat schrijver dezes ook nog uit andere bronuen en zijne persoonlijke ervaring zou kunnen aauvoeren, laat hij achterwege, en beperkt hij zich tot de opgegeven voor zoo ver hem bekend is - tot heden niet tegengesproken officieele bron, 
Uit Meppel: "De vahouders konden slechts lage prijeen bedingen, zoowel een gevolg van de malaise, als van de doorgaans ruime hoeveelheid inferieure sonrten, die ter markt werden gebracht. Te betreuren blijft het dan ook, èn voor het geldelijk voordcel van de veehouders, èn voor het behoud van deu gunstigen naam onzer markt, dat de veehonders niet algemeen die zorg an de bereiding van boter wijden, die het artikel bij de toenemende zorg, die men elders meer en meer daaraan besteedt, 200 zeer voodig heeft."

Uit Deventer : "De boterhandel gaf weinig reden tot tevredenheid. Behoudens eenige gunstige uitzonderingen, liet de kwaliteit van het artikel veel te wenschen over en waren de prijzen bijzonder laag."

En nog uit Deventer deze behartigingswaardige woorden:

"Zoo laus de landbouwers niet leeren inzien, dat alleen uitstekende kwaliteit, verpakt in zuivere en nette vaten, eene levenskwestie voor hen is, gaat de boterhandel viet slechts in deze streek, maar ook in andere provinciën van ons vaderland een treurige tockomst te gemoet. -.. - - De vreemdeling beeft geen vertrouwen meer in het Hollandsch product, omdat hij te veel wordt bedrogen door inferienre kwaliteit en vermengd goed, zoodat Duitschland nu reeds de plaats van Nederland op de buitenlandsche markten begint in te nemen."

En dat er inderdaad ontzettend groot verschil is tusschen boter en boter op onze markten, blijkt uit 't zelfde Landbouw-verslag bl. 428 en 429.

Daar wordt gewag gemaakt van de gemiddelde prijzen van boter ter markt in Friesland, te Meppel, te Zwolle en te Delft, en een verschil geconstateerd van gemiddeld 18 eents per kilo. De kwaliteit beheerscht den prijs, gelijk er zéér terecht wordt opgemerkt:

"Eeu verschil van 70 cents per kilogr., zooals te Meppel en te Delft plaats "heeft, is veel te groot om dit aan andere ourzaken dan aan de bereiding toe te "schrijven; zelfs een verschil vau 20 cts., zooals te Meppel en te Zwolle plaats "vond, is al te groot om viet aan een meer of mindere onversehilligheid bij de "bereiding te denken."

En nog dáár op bl. 429:

"Men dient voorzichtig te zijn dat men door eigen schuld zich niet met noy "lager prijzeu tevredeu moet stelles eu dit zal het geval worden als men niet "alle krachten blift inspannen om boter van le kwaliteit en niet anders dan deze "te bereidew."

Tot een en ander wensch ik mij voor 't oogenblik te beperken. Vergis ik mij niet ten eenenmale, dan geeft 't geen ik mededeelde, ruimschoots stof voor ernstige overweging. De dagen, die wij beleven, eischen inspanning, onverdroten. En waar nu -- gelijk uit't bovenstaande zoo overtuigend blijlkt - verslapping is waar te nemen in zake de hoedanigheid van ons botergemaak - daar zullen wij het afleggen, geheel ter markt te Londen, nog erger dan tot heden - - met boter van inferieure kwaliteit - - en bovendien, 
als de Regeering daaraan niet ten langen leste een einde maakt, met invoer onder valschen naam van eonig mixtum, gevaarlijk vooral voor de importeurs van natuurboter van inferieure hoedanigheid. Supra-eerste-kwaliteit-boter brengt geld op en is de gevaarlijkste concurrent te Londen zelfs tegenover Deensche boter. Naar mijne persoonlijke overtuiging maken wij - mits wij slechts willen boter, die minstens even goed, zoo niet beter is dan de Deensche - maar ook heel wat anderen rommel.

Den Haag, 27 Nov.

Dr. L. MUlder. 